\title{
ANALISIS UJI TIDAK MERUSAK PADA SAMBUNGAN LAS LAMBUNG FRAME 103 BAGIAN KAMAR MESIN KAPAL PATROLI 73 DENGAN METODE RADIOGRAPHY TEST
}

\author{
Sulaiman, Budi Utomo, I Putu Agung Ardi Wijana \\ Program Studi Diploma III Teknologi Perancangan dan Konstuksi Kapal, Departemen Teknologi Industri, \\ Sekolah Vokasi, Universitas Diponegoro, \\ Jl. Prof. Soedarto, SH, Kampus Undip Tembalang, Semarang, Indonesia 50275
}

\begin{abstract}
Non-Destructive Test is a supporting tool that is highly relied upon by the activities of controlling and ensuring the quality of a welding. Radiography test is one of the non-destructive tests that uses gamma rays that can penetrate almost all metals so that it can be used to reveal defects or discrepancies behind metal walls or within the material itself. The purpose of this paper is to know, plan a non-destructive testing activity with radiography test which includes the understanding along with the equipment needed during the testing process, what devices contribute to the testing process, as well as knowing the advantages and disadvantages of the test radiography. The method used in This writing is by experiment with welding connection frame 103 Patrol Ship 73 engine rooms. Radiography Test results found no welding defects on the inside of the welding as deep as a plate thickness, so that otherwise passed the checking received by BKI. Good preparation and consideration are needed before conducting this test.
\end{abstract}

Keywords: NDT; radiography test; welding; patrol boat.

\section{PENDAHULUAN}

Uji Tanpa Merusak merupakan sarana penunjang yang sangat diandalkan oleh kegiatan pengendalian dan pemastian mutu suatu pengelasan. Konstruksi kapal umumnya berbahan baja, sehingga di perlukan suatu proses pengelasan yang tepat[1]. Kunci dari analisa struktur suatu konstruksi terdapat pula pada elemen setiap sambungannya[2]. Sebagai salah satu metode untuk memastikan mutu pengelasan maka Non DestructiveTest atau biasa disebut NDT dapat digunakan sebagai sarana mengidentifikasi kecacatan pada material. NDT dapat diartikan sebagai pemeriksaan yang ditujukan untuk mengidentifikasikan adanya kecacatan atau kelemahan pada bahan material tanpa merusak ataupun menghancurkan benda atau spesimen.

Pada dasarnya, pengujian ini dilakukan agar menjamin bahwa material yang kita gunakan masih aman dan belum melewati damage tolerance. NDT terdiri dari beberapa metode : Liquid Penetrant Inspection, Eddy Current, Magnectic Test dan Radiography Test [3].

Radiografi adalah salah satu uji tanpa merusak yang menggunakan sinar $\mathrm{X}$ atau sinar gamma yang mampu menembus hampir semua logam kecuali timbal dan material padat lainnya sehingga dapat digunakan untuk mengungkapkan cacat atau ketidaksesuaian dibalik dinding metal atau didalam bahan itu sendiri[4], lihat Gambar 1 . Didalam pengelasan, radiografi merupakan faktor penting untuk menentukan mutu internalnya secara cepat sebelum melangkah ke jenis uji mutu yang lainnya seperti uji merusak. Radiografi menggunakan penetrating radiation yang diarahkan langsung pada material.

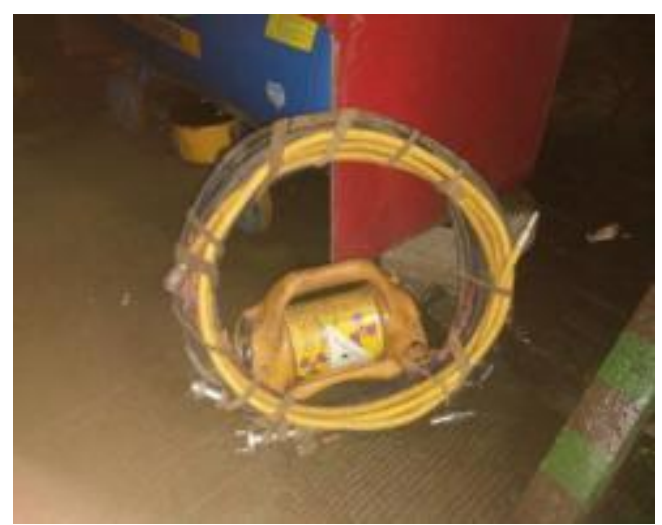

Gambar 1. Peralatan Radiografi test

Intensitas radiasi yang ditembakkan pada material sangat bergantung pada berat jenis dan ketebalan material. Hasil dari pengujian akan ditampilkan pada film atau monitor[5]. Proses produksi kapal terutama pada sambungan pengelasan bagian lambung layak mendapat perhatian khusus. Pada bagian lambung terutama pada lajur pertemuan pengelasan sangat riskan untuk terjadi cacat pada pengelasannya. Salah satunya adalah bagian kamar mesin kapal. Bagian ini merupakan bagian yang sangat penting, dikarenakan sebagai sumber utama proses pembakaran dan kapal mendapatkan daya dorong dari mesin utama. Jika pada bagian kamar mesin mengalami kebocoran maka dapat dipastikan kapal mengalami kegagalan dalam beroperasi[1].

Di dunia pengelasan, teknik radiasi memang memiliki peran yang cukup besar dan dominan dalam menentukan mutu suatu sambungan pengelasan. Selain itu juga dapat digunakan sebagai penentu batasan penerimaan atau penolakan dari 
hasil pengelasan. Namun demikian bukan berarti radiografi test juga merupakan teknologi yang sempurna, karena terdapat kelemahan yang cukup menyulitkan pihat inspektor dalam mendeteksi cacat - cacat pengelasan yang terjadi[6].

Dari review terdahulu Non destructive test oleh Gholizadehtahun 2016 dengan judul "A Review Of Non-Destructive Testing Methods of Composite Materials" menjelaskan bahwa setiap metode yang digunakan untuk peroses pengujian tidak merusak ini tergantung dari aplikasi penggunannya serta komposisi dari bahan utamanya. Hal ini menunjukan pengunaan aplikasi pengujian tidak merusak ini memiliki beberapa kelebihan dan keuntungan yang dapat diterapkan sesuai dengan penempatannya. Diantaranya terdapat Uji Visual, Uji Radiography, Uji Magnetic, Uji Ultrasonic[7].

Sedangkan aplikasi pada bidang industri juga telah dilakukan pengkajian sebelumnya, menurut Amenabar tahun 2011 dengan penelitiannya yang berjudul "Comparison and Analysis of NonDestructive Testing Techniques Suitable for Delamination Inspection in Wind Turbine Blades" hasilnya menjelaskan bahwa dengan pengujian tidak merusak maka dapat mengetahui analisa dari perbandingan uji eksperimen terhadap baling-baling turbin antara bahan E-glass/polyester dan Eglass/epoxy. Untuk jenis pengujiannya dengan menggunakan Uji Visual, Uji Radiography, Uji Magnetic, Uji Ultrasonic. Hal ini senada dengan review sebelumnya bahwa NDT sangat efektif dilakukan pada bidang industri[8].

Demikian juga dalam bidang industri penerbangan penelitian sebelumnya yang dilakukan oleh Andrzej pada tahun 2015 dengan judul "Damage Identification In Aircraft Composite Structures: A Case Study Using Various NonDestructive Testing Techniques"menunjukan hasil jika pengujian tidak merusak ini dapat juga diaplikasikan untuk menilai dan mengevaluasi suatu material pada struktur yang mengalami kelelahan akibat adanya getaran yang terjadi. Getaran tersbut dapat ditimbulkan dari sustensi karena adanya sumber getaran atau berdasarkan kontak dengan benda atau bidang di luarnya. Bahan yang digunakan adalah polimeric komposit sehingga senada dengan penelitain sebelumya,dengan metode pengujian yang digunakan Uji Visual, Uji Radiography, Uji Magnetic, Uji Ultrasonic. Ha ini menunjukan pengujian tidak merusak dapat mewakili pendeskripsian kondisi suatu material[9].

Relevansi yang terlihat dari penelitian ini adalah masih memiliki kesinambungan dari pengujian tidak merusak. Hal ini memberikan hipotesis sementara bahwa sambungan pengelasan pada industri perkapalan cukup penting sama halnya dengan penelitian - penelitian yang dilakukan sebelumnya. Terutama berkaitan dengan matrial sambungan pengelasan, perlu adanya hasil yang mengkorelasi antara teori dan penelitian terdahulu sehingga terciptanya suatu gagasan untuk pengujian tidak merusak pada sambungan pengelasan industri bidang perkapalan. Tentunya sangat menarik untuk di teliti mengingat bagian ini merupakan ranah dari teknologi rekayasa terapan.

Bagian kamar mesin merupakan bagian yang terpenting dalam sebuah sistem gerak kapal. Kamar mesin atau engine room dapat dikatakan merupakan salah satu kompartemen pada kapal yang terdapat sistem permesian yang saling berinegerasi untuk menggerakan kapal. Pada kamar mesin terdapat deck opening yaitu engine casing, rumah geladak, bangunan atas serta perlengkapan penggerak kapal seperti mesin utama, mesin bantu, tangki-tangki, pipa-pipa dan lain-lain. Oleh karenanya konstruksi pada bagian kamar mesin harus kuat untuk menahan beban dan gaya yang besar. Sambungan pengelasan pada lambung kapal bagian kamar mesin pun juga perlu mendapat perhatian khusus[1].

Secara garis besar batasan masalah dalam penulisan ini adalah bagian yang akan dilakukan pengujian dengan metode radiografi test pada bagian lambung kapal bagian kamar mesin ,kondisi welder dan tempat kerja berada keadaan yang kondusif di dalam workshop. Cuaca ketika pengujian NDT dengan menggunakan Radiografi test cerah.Pengujian ini perlu dilakukan mengingat pada fram 103 merupakan pertemuan perempatan dari sambungan pengelasan, sehingga cukup memeiliki resiko terjadi kebicoran atau cacat pengelasan.

Sehingga tujuan dari penelitian ini adalah untuk mengetahui dan merencanakan suatu kegiatan pengujian tidak merusak dengan metode radiografi test pada sambungan pengelasan, saat proses pengetesan maka dapat diketahui perangkat apa saja yang turut andil dalam proses (dari before, during, after) pengetesan, serta mengetahui keuntungan dan kerugian dari metode radiografi tes sebagai jawaban dari analisa pada penelitian ini.

\section{Non Destructif Test}

Non Destructive Testing (NDT) adalah aktivitas tes atau inspeksi terhadap suatu benda untuk mengetahui adanya cacat, retak, atau discontinuity lain tanpa merusak benda yang kita tes atau inspeksi[10]. Pada dasarnya, tes ini dilakukan untuk menjamin bahwa material yang kita gunakan masih aman dan belum melewati batas teleransi kerusakan. Biasanya NDT dilakukan selama dan diakhir proses fabrikasi, untuk menentukan suatu komponen dapat diterima setelah melalui tahaptahap fabrikasi. NDT ini dijadikan sebagai bagian dari kendali mutu komponen. Selnajutnya NDT dilakukan setelah komponen digunakan dalam jangka waktu tertentu tujuannya adalah menemukan kegagalan parsial sebelum melampaui damage tolerance-nya[11] 


\section{Radiografi test}

Radiografi NDT (Non Destructive Test) adalah pengujian tanpa kerusakan menggunakan sinar-X merupakan sebuah aktifitas tes atau pengujian terhadap suatu objek (material, rangka, dll) dengan menggunakan sinar gama atau biasa disebut sinar- $\mathrm{X}$ untuk mengetahui kandungan dari objek dan kompnen-komponen yang diuji apa saja yang terkandung di dalamnya serta tercatat secara jelas dan akurat, serta menguji kondisi dan kualitas objek tanpa melampaui batas toleransi kerusakan objek. Sehingga dengan kata lain objek yang diujikan dijaga kualitasnyanya tidak perlu merusak objek untuk mendapatkan hasil yang maksimal biasanya pengujian X-Ray NDT mengandalkan analisis pengamatan jangka waktu yang berkala[12]. Pada umumnya sinar-X diaplikasikan dalam dunia medis yaitu diagnosis gambar medis dan krisalografi sinar-X, Sinar-X adalah bentuk dari radiasi ion dan dapat berhaya, sinar-X atau sinar gama merupakan salah satu bentuk dari radiasi elektromagnetik dengan panjang gelombang berkisar antara 10 nanometer ke 100 pikometer (sama dengan frekuensi dalam rentang 30 petahertz - 30 exahertz) dan meiliki energi dalam rentang $100 \mathrm{eV}-100 \mathrm{KeV}$ [5].

Adapun gambaran dari mekaisme kerja radiografi test dapat dilihat pada Gambar 2.

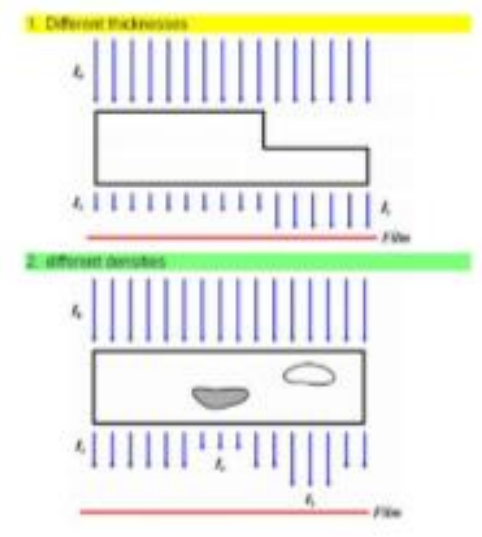

Gambar 2. Mekanisme kerja radiografi test

Tujuan dilakukan pengujian Radiografi untuk mendeteksi cacat pada permukaan benda ataupun didalam benda, mengukur geometri benda, menentukan reaksi kimia pada benda, pengujian dilakukan untuk mendapatkan kuliatas barang yang baik, menghindari kecelakaan, mengurangi biaya pengeluaran yang berlebih.

Pengujian radiografi mempuyai sensitivitas yang tinggi. Cara kerja dari radiografi adalah alat tersebut dipasang untuk dilakukan pengujian dan dipancarkan sinar X-ray ke benda yang ingin dilakukan pengujian, memancarkan sinar X-ray yang bisa menembus pada material yang diperiksa untuk mengetahui jenis material atau reaksi kimia yang ada pada benda tersebut, setelah sinar X ditembakkan ke benda tersebut, akan mendapatkan data dan bayangan dari benda tersebut. Jika benda tersebut terdapat kecacatan maka hasilnya akan ketahuan[6].

\section{METODE PENELITIAN}

Dalam proses penelitian ini dibutuhkan data data dari obyek yang akan dianalisis. Adapun prosespengambilan data terbagi menjadi beberapa tahap , antara lain:

\section{Studi Lapangan}

Dalam penelitian ini penulis perlu melakukan studi lapangan dan wawancara secara langsung dengan pihak - pihak yang berkaitan dengan penelitian ini dan bertujuan untuk melengkapi kebutuhan data dalam pengerjaan penelitian ini,adapun studi lapangan tersebut antara lain :

- Pengambilan Data Penelitian

Data yang dibutuhkan dalam pengerjaan penelitian ini adalah Data Primer dan Data Sekunder.

- Metode Pengambilan Data

Dalam proses pengambilan data, ada beberapa metode yang digunakan dalam pengambilan data tersebut, diantaranya adalah metode observasi dan metode wawancara.

- Tempat Penelitian ini dilakukan pada Industri Galangan Kapal PT. Daya Radar Utama,Jakarta.

- Mempelajari sistematika penelitian terdahulu yang akan dikemukakan dari berbagai macam referensi baik berupa buku, majalah, artikel, jurnal dan melalui internet.

- Setelah melakukan pengamatan dan pengambilan data dilapangan, maka selanjutnya data tersebut dilakukan proses analisis dan pembahasan.

- Semua hasil pengolahan data berupa pemaparan analisis, rangkuman hasil analisis yang terjadi kemudian dilakukan pengelompokan agar mudah dalam penyusunan laporan.

\footnotetext{
Alat

Penelitian ini menggunakan beberapa peralatan untuk mempermudah melakukan proses pengujian radiografi test, seperti Source Tube, Film radiasi, Lead Screen / Plat PB, Film Viewer, Surveymeter, Calimator.

Source Tube memiliki fungsi sebagai pusat menembakan radiasi dari tabung radiasi ke tempat yang akan dilakukan radiogrphy test, lihat Gambar 3. Film radiasi digunakan untuk membaca data. Kecepatan dari pembacaan film hasil radiasi tergantung dari tipe film yang digunakan.
} 


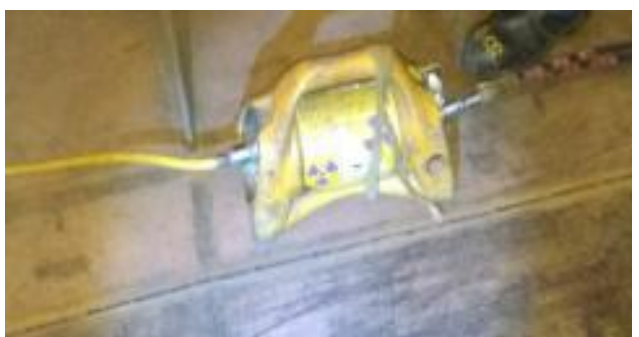

Gambar 3. Source Tube

Lead Screen / Plat PB memiliki ketebalan sekitar $0.125 \mathrm{~mm}$ untuk sisi depan dan sisi belakang dari film radiasi yang berbahasan dasar timah hitam. Lead screen sendiri memiliki fungsi untuk mengembangkan radiasi yang terperangkap ke dalam film agar saat proses pembacaan hasilnya lebih jelas, lihat Gambar 4.

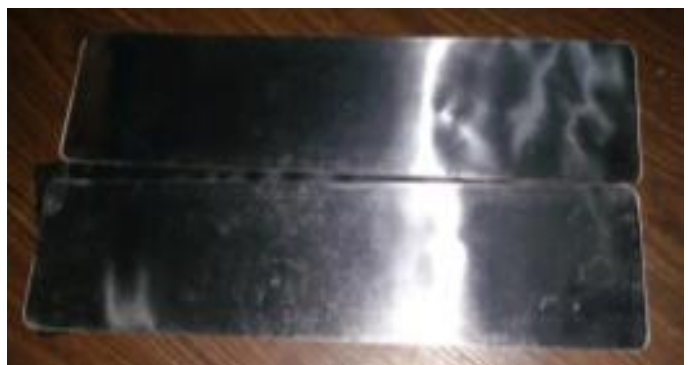

Gambar 4. Lead Screen

Film Viewer adalah sebuah alat yang memiliki kegunaan untuk membaca hasil dari film radiografi, lihat Gambar 5.

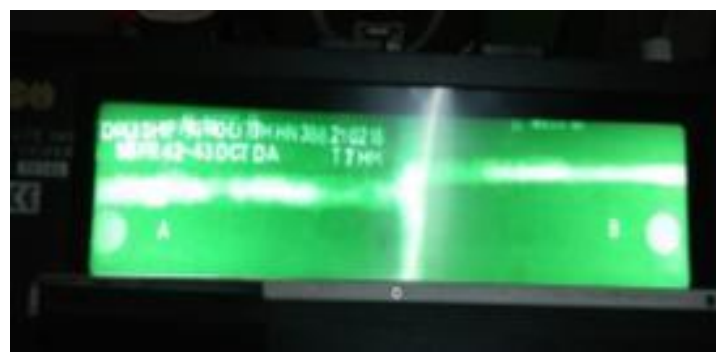

Gambar 5. Film Viewer

Surveymeter adalah alat yang memiliki fungsi untuk mendeteksi kadar radiasi pada saat proses penembakan. Jarak aman dari sumber radiasi adalah $2,5 \mathrm{mr} / \mathrm{hr}$, lihat Gambar 6 .

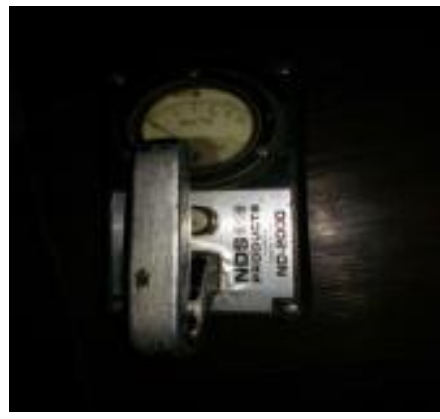

Gambar 6. Surveymeter
Calimator berfungsi untuk memfokuskan tembakan radiasi agar tidak menyebar dengan cara memasangkan alat ini di source tube, lihat Gambar 7.

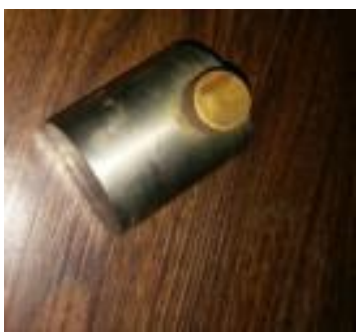

Gambar 7. Calimator

\section{HASIL DAN PEMBAHASAN}

Adapun data yang didapatkan pada data ukuran utama kapal, lihat Gambar 8, adalah sebagai berikut :

$\begin{array}{ll}\text { Nama Kapal } & : \text { Kapal Patroli } 73 \\ \text { LOA } & : 73.67 \mathrm{M} \\ \text { LBP } & : 68.00 \mathrm{M} \\ \mathrm{B} & : 11.35 \mathrm{M} \\ \mathrm{H} & : 5.50 \mathrm{M} \\ \mathrm{T} & : 3.20 \mathrm{M} \\ \text { Speed } & : 18 \mathrm{Knot}\end{array}$

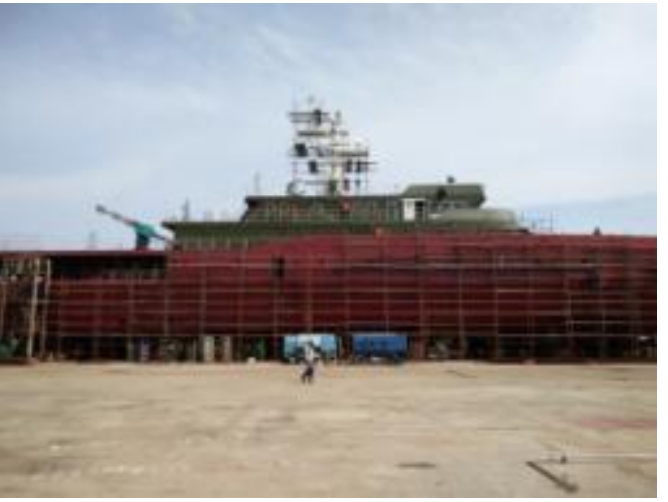

Gambar 8. Pembangunan Kapal Patroli 73

Pada Radiography Test kali ini terdapat beberapa perwakilan titik sambungan pengelasan pada beberapa bagian (seperti bagian lambung, tangki dan lain-lain) yang akan dilakukan proses pengetesan. Bagian yang diuji hanya sebagai contoh yang akan ditunjukkan kepada class dan pada sambungan las yang cukup sulit. Salah satunya pada frame 103 yaitu di bagian antara sekat kamar mesin (engine room) dengan Auxilary Room, lihat Gambar 9. 


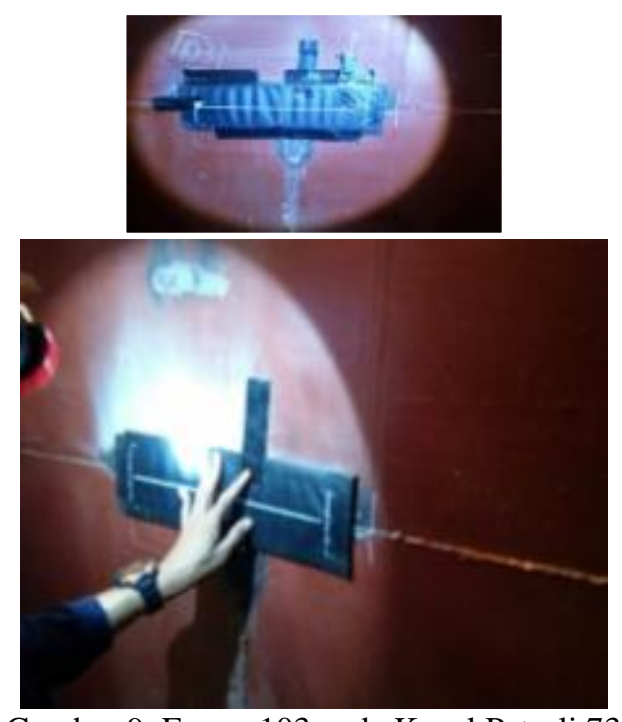

Gambar 9. Frame 103 pada Kapal Patroli 73

Beberapa Faktor dan pertimbangan pemilihan loksi tempat dilakukannya pengujian Radiography Test adalah :

- Kesepakatan antara pihak class dengan galangan.

- Pada sambungan las yang memiliki tingkatkesulitan yang tinggi.

- Pada bagian yang penting (seperti tangki, sekat kedap dan lain-lain)

Jarak sumber terhadap film perlu ditentukan. Minimum adalah 1,5 kali panjang benda atau bagian yang di uji. Makin panjang jaraknya makin baik, karena akan menghasilkan data yang makin kecil. Standart maksimum jarak sumber terhadap film telah ditentukan dalam standar yang umum digunakan yaitu ASME (American Society of Mechanical Engginering).

Durasi penembakan harus benar-benar sesuai dengan durasi pencucian film. Perlu adanya ahli yang berkompeten dan berpengalaman dalam melakukan pencucian film dan penembakan radiasi. Jika durasi proses penembakan terlalu cepat dibandingkan proses pecucian, maka hasil dari film akan terlihat gelap, begitupun sebaliknya.

Adapun langkah kerja dari radiografi test adalah sebagai berikut ini :

- Marking pada tempat atau material pengelasan yang akan diuji.

- Sebelum pemasangan film radiografi di tempat pengelasan, film terlebih dahulu di pasang di antara plat PB (Lead Screen) agar radiasi yang ditembakan ke film dapat terperangkap kedalam film.

- Kemudian dilakukan pemasangan film di tempat yang sudah dimarking.

- Siapkan tabung radiasi, source tube dan alat pemantik radiasi. Namun perlu diperhatikan untuk penembakan radiasi bahwasanya pada saat penembakan radiasi, untuk posisi source tube harus berada di balik film radiasi yang sudah dipasang di material yang akan diuji. Tindakan ini dilakukan bertujuan agar film tidak terpapar langsung oleh radiasi, apabila film terpapar langsung oleh radiasi maka film akan terbakar. Selain itu juga, source tube dengan film harus sejajar dan jarak antara source tube dengan film harus sesuai dengan identifikasi.

- Gunakan surveymeter untuk mengetahui jarak aman dari radiasi pada saat proses penembakan berlangsung. Khusus untuk bagian atau tim operator menggunakan alat khusus yang dipasang di pakaian guna mengurangi kadar radiasi yang terpapar dalam tubuh.

- Jika menurut operator lingkungan penembakan sudah dirasa aman, maka proses penembakan dilakukan melalui alat pemantik radiasi.

- Setelah penembakan radiografi, oprator akan menutup kembali source tube yang awalnya terbuka untuk mengunci radiasi di dalam tabung radiasi supaya tidak menyebar ke lingkungan sekitar.

- Kemudian jika source tube sudah ditutup kembali, maka tabung radiasi dimatikan. Setelah itu, lingkungan atau daerah tempat penembakan radiografi sudah aman dari radiasi radiografi.

- Setelah itu, tim operator membawa film yang sudah ditembak ke tim AR (ahli radiografi) untuk dilakukan proses pencucian film dan pembacaan film radiografi.

- Untuk pembacaannya maka dilakukan pencucian terlebih dahulu sebelum dibaca di dalam ruangan khusus. Ruangan tersebut harus gelap dan tertutup (untuk jenis film blue maka hanya diperbolehkan warna merah untuk menerangi ruangan sedangkan untuk jenis film green hanya diperbolehkan warna dasar atau warna sekunder). Untuk jenis film blue hanya tahan warna merah redup saat proses pencucian namun hasilnya sangat sensitive sedangkan untuk jenis film green tahan dengan beberapa warna primer pada saat proses pencucian namun hasilnya kurang sensitif.

- Jika proses pencucian film sudah selesai, maka film akan dibaca menggunakan film viewer sehingga dapat terihat dengan jelas kecacatan material yang sedang diuji. Tim akan membaca film apakah film layak diterima atau harus di reject. Hasil film harus sesuai dengan Standar Penerimaan Film.

- Jika film reject atau ditolak oleh tim AR, maka AR akan mengisyaratkan kepada tim operator dan tim safety untuk dilakukan penembakan ulang. Namun, jika hasil film lolos dari criteria Standar Penerimaan Film, maka tim AR akan membaca cacat dari material yang diuji darihasil film radiografi. Setelah itu, tim AR akan menulis berita acara mengenai cacat atau 
tidaknya material yang diuji dan diserahkan kepada QC (Quality Control) dari pihak galangan dan class untuk ditindaklanjuti.

- Untuk pelaksanaan dari radiografi test sendiri harus benar-benar aman dari orang lain dan harus dilakukan di malam hari, penjagaan yang ketat dari pihak galangan maupun tim radiografi itu sendiri.

Radiografi test sendiri memiliki hubungan dengan tingkat kerapatan material[11]. Hal tersebut tergambar dalam sebuah grafik yang menunjukan hubungan antara energi yang di perlukan serta tingkat kerapatan dari bahan yang akan diujikan, lihat Gambar 10.

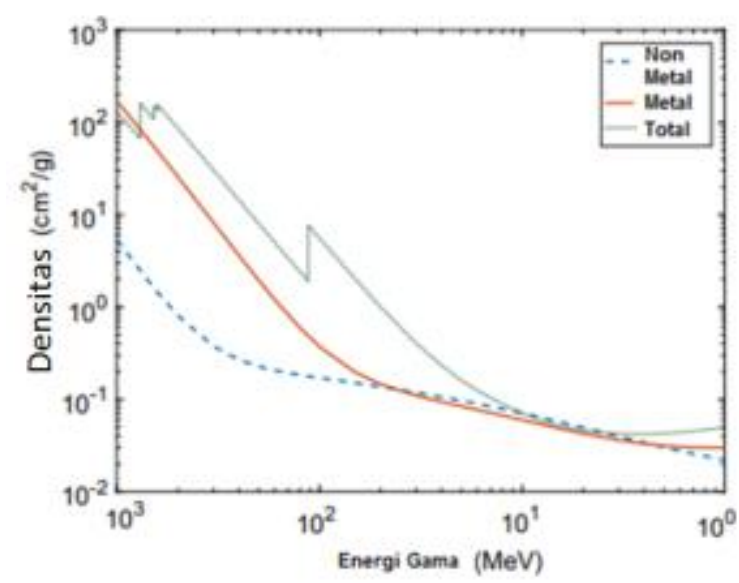

Gambar 10. Grafik penggunaan sinar gama

Dari analisis diatas dapat diketahui bahwa perpaduan antar logam ataupun jenis komposit dapat dilakukan pengujian dengan radiografi test. Semakin besar tingkat kerapatan benda uji maka semakin besar juga energi yang di perlukan untuk penggunaan sinar gama dalam radiografi test tersebut. Begitu juga dengan sebaliknya jika kerapatan material yang akan diuji semakin renggang maka energi sinar gama yang dibutuhkan juga semakin sedikit. Pada benda non metal memiliki kecenderungan material paduan atau komposit sehingga terdapat kemungkinan tidak begitu rapat seperti material metal.

Adapun keuntungan dari penggunaan Radiografi Test diantaranya :

- Dapat digunakan di berbagai jenis material.

- Menghasilkan visual image yang permanen.

- Dapat memperlihatkan kondisi asli bagian dalam material.

- Dapat memperlihatkan bagian cacat secara detail.

\section{KESIMPULAN}

Non Destructif Test dapat digunakan sebagai solusi untuk mengetahui hasil pengelasan tanpa merusak. Salah sataunya adalah dengan menggunakan metode radiografi test. Meskipun banyak keuntungan yang diperoleh namun juga perlu diperhatikan pertimbangan dan persiapan sebelum melakukan pengujian ini. Hasil pengujian Radiografi Test terhadap sambungan pengelasan frame 103 bagian kamar mesin Kapal Patroli 73 tidak ditemukan cacat pengelasan pada bagian dalam pengelasan sedalam tebal plat, sehingga dinyatakan lolos pengecekan. Penggunaan sinar gama berdasarkan analisa didapatkan informasi teknis dengan bahan metal maksimum yaitu $20 \times 10^{3} \mathrm{MeV}$ dengan kerapatan material $1,5 \times 10^{2} \mathrm{~cm}^{2} / \mathrm{g}$.

\section{DAFTAR PUSTAKA}

1. M. I. Haith et al., 2017, Radiographic modelling for NDE of subsea pipelines, NDTE Int., vol. 86, pp. 113-122.

2. S. F. Khristyson, I. P. Mulyatno, and A. Trimulyono, 2014, Analisa Kekuatan Konstruksi Internal Ramp Sistem Steel Wire Rope Pada KM. Dharma Kencana VIII Dengan Metode Elemen Hingga, J. Tek. Perkapalan, vol. 2, no. 3.

3. F. M. Suyama, M. R. Delgado, R. Dutra da Silva, and T. M. Centeno, 2019, Deep neural networks based approach for welded joint detection of oil pipelines in radiographic images with Double Wall Double Image exposure, NDT E Int., vol. 105, pp. 46-55.

4. L. Yenumula et al.,2019, Radiographic evaluation of gas tungsten arc welded joints used in nuclear applications by $\mathrm{X}$ - and gammarays, NDT E Int., vol. 102, pp. 144-152.

5. S. Zheng, J. Vanderstelt, J. R. McDermid, and J. R. Kish, 2017,Non-destructive investigation of aluminum alloy hemmed joints using neutron radiography and X-ray computed tomography, NDT E Int., vol. 91, pp. 32-35.

6. F. Prade et al., 2017, Nondestructive characterization of fiber orientation in short fiber reinforced polymer composites with $\mathrm{X}$ ray vector radiography, NDT E Int., vol. 86, pp. 65-72.

7. S. Gholizadeh, 2016, A review of nondestructive testing methods of composite materials, Procedia Struct. Integr., vol. 1, pp. 50-57.

8. I. Amenabar, A. Mendikute, A. López-Arraiza, M. Lizaranzu, and J. Aurrekoetxea, 2011, Comparison and analysis of non-destructive testing techniques suitable for delamination inspection in wind turbine blades, Compos. Part B Eng., vol. 42, no. 5, pp. 1298-1305.

9. A. Katunin, K. Dragan, and M. Dziendzikowski, 2015, Damage identification 
in aircraft composite structures: A case study using various non-destructive testing techniques, Compos. Struct., vol. 127, pp. 1-9.

10. O. Zahran, H. Kasban, M. El-Kordy, and F. E.

A. El-Samie, 2013, Automatic weld defect identification from radiographic images, NDT E Int., vol. 57, pp. 26-35.

11. H. Kasban, O. Zahran, H. Arafa, M. El-Kordy, S. M. S. Elaraby, and F. E. Abd El-Samie, 2011, Welding defect detection from radiography images with a cepstral approach, NDT E Int., vol. 44, no. 2, pp. 226-231.

12. M. Thornton, L. Han, and M. Shergold, 2012, Progress in NDT of resistance spot welding of aluminium using ultrasonic C-scan, NDT E Int., vol. 48, pp. 30-38. 